Correspondence

lan R. Poxton

i.r.poxton@ed.ac.uk

Received 23 July 2009

Accepted 25 September 2009

\section{Potential use of a liposome-encapsulated mixture of lipopolysaccharide core types (R1, R2, R3 and R4) of Escherichia coli in controlling colisepticaemia in chickens}

\author{
D. R. Anuruddhika Dissanayake, ${ }^{1}$ Thula G. Wijewardana, ${ }^{1}$ \\ Gnana A. Gunawardena ${ }^{2}$ and lan R. Poxton ${ }^{3}$ \\ ${ }^{1}$ Department of Pathobiology, Faculty of Veterinary Medicine and Animal Science, University of \\ Peradeniya, Peradeniya, Sri Lanka \\ ${ }^{2}$ Division of Microbiology, Veterinary Research Institute, Gannoruwa, Sri Lanka \\ ${ }^{3}$ Medical Microbiology, Centre for Infectious Diseases, University of Edinburgh College of Medicine \\ and Veterinary Medicine, The Chancellor's Building, 49 Little France Crescent, Edinburgh EH16 \\ 4SB, UK
}

\begin{abstract}
Infections caused by Escherichia coli have an economically significant impact on the poultry industry and a non-serotype-specific vaccine appears to be the most logical method of controlling them. The core oligosaccharide-lipid A region of bacterial lipopolysaccharide (LPS) is well conserved and highly immunogenic but toxic. This study determined the possible use of a liposome-encapsulated mixture of rough LPSs of core types R1, R2, R3 and R4 in controlling infections caused by $E$. coli in chickens. The liposome which encapsulated the LPS consisted of egg phosphatidylcholine, bovine brain phosphatidylserine and cholesterol. As determined by Limulus amoebocyte lysate assay, incorporation of LPS into the liposome reduced the endotoxicity of LPS to $0.7 \%$ of its initial value. When tested on a chicken macrophage cell line (HD11), liposome-incorporated LPS produced a significantly lower amount of nitric oxide $(<5 \mu \mathrm{M})$ than that produced by free LPS $(22 \mu \mathrm{M})$. Transcription of the genes for interleukin- $1 \beta$ and inducible nitric oxide synthase was lower in cells treated with liposome-incorporated LPS than in cells treated with free LPS. When chickens were immunized with $0.2 \mu \mathrm{g}, 1 \mu \mathrm{g}$ and $5 \mu \mathrm{g}$ liposome-encapsulated mixture of LPS core types, the antibody response increased with increasing dose. When challenged with the virulent E. coli O78 strain, the birds which received $1 \mu \mathrm{g}$ liposome-encapsulated LPS and $5 \mu \mathrm{g}$ LPS had significantly lower lesions scores $(P<0.05)$ and high body weight when compared with the birds in the control group as well as with the birds immunized with a suboptimal dose $(0.2 \mu \mathrm{g})$ of liposome-encapsulated LPS.
\end{abstract}

\section{INTRODUCTION}

The potential of controlling Escherichia coli infections in commercial poultry through vaccination has been explored widely over the past several decades. In these attempts, live or killed bacteria and their various cellular components have been used to immunize chickens (Deb \& Harry, 1976; Arp, 1980; Nagaraja et al., 1984; Gyimah \& Panigrahy, 1985; Frommer et al., 1994; Kariyawasam et al., 2002). However, the involvement of more than 60 serotypes in causing avian E. coli infections limited the use of these serotype-specific vaccines in the field. An effective vaccine to control these infections should be directed against

Abbreviations: IFN- $\gamma$, gamma-interferon; IL-1 $\beta$, interleukin- $1 \beta$; iNOS, inducible nitric oxide synthase; LAL, Limulus amoebocyte lysate. antigenic determinants shared by all these serotypes. Serotype specificity of Gram-negative bacteria is determined by the O-polysaccharide side chains of bacterial LPS (Galanos \& Lüderitz, 1984). In E. coli, the antigenic diversity expressed by the O-polysaccharide chains is extensive, whereas that of LPS core structures and the lipid-A component is limited (Westphal, 1975; Poxton, 1995).

In the process of developing a broadly cross-reactive and cross-protective vaccine, the core oligosaccharide region of bacterial LPS has attracted much attention. Of the three highly immunogenic structural regions of LPS, the core oligosaccharide region is well conserved and has proven ability to protect hosts against heterologous challenge (Poxton, 1995; Bennett-Guerrero et al., 2000). There are 
only five different LPS core types present in E. coli and four core types, R1-R4, are reported to be common among avian E. coli (Dissanayake et al., 2008). Therefore, a vaccine incorporating these four core types may induce wide protection.

Activation of myeloid cells, non-myeloid cells and other components of the innate defence system by LPS induces production of a wide range of pro-inflammatory mediators (Wigley \& Kaiser, 2003). Excessive production of these mediators induces systemic pathological effects characterized by fever, hypotension, disseminated intravascular coagulation, multi-organ failure, shock and death (Morrison \& Ryan, 1987; Müller-Loennies et al., 2005). Poultry are said to be more tolerant than mammals to LPS, but fever, anorexia, decreased growth and respiratory capacity and death after being exposed to LPS is not uncommon among poultry (Parmentier et al., 2008). Early studies carried out on mammals demonstrated that the interaction of LPS with macrophages can be modified without altering its immunogenicity by incorporating LPS into phospholipid vesicles called liposomes (Dijkstra et al., 1987, 1988; Bennett-Guerrero et al., 2000; Erridge et al., 2002). The present study was carried out to determine the possible use of a liposome-encapsulated mixture of LPS core types in controlling E. coli infections in chickens.

\section{METHODS}

Extraction of LPS by the aqueous phenol method. LPS was extracted by the aqueous phenol method (Hancock \& Poxton, 1988) from four rough E. coli strains isolated from chickens representing the LPS core types R1, R2, R3 and R4. Freeze-dried LPS was dissolved at $5 \mathrm{mg} \mathrm{ml}^{-1}$ in pyrogen-free water and traces of endotoxin proteins were removed from the LPS as described by Manthey \& Vogel (1994).

Preparation of liposomes. Multilamellar vesicles were prepared using egg phosphatidylcholine, bovine brain phosphatidylserine and cholesterol (Sigma) dissolved in chloroform in a $4: 1: 4$ molar ratio as described by Dijkstra et al. (1989) and modified by Bennett-Guerrero et al. (2000). Purified rough LPSs (Ra chemotype) of core types R1, R2, R3 and R4 extracted by the aqueous phenol method were suspended in $0.1 \%$ triethylamine and added to the dried lipid films in four flasks in $1000: 1,100: 1,10: 1$ and $1: 1(\mathrm{w} / \mathrm{w})$ lipids: LPS ratios. Suspensions were subjected to vigorous vortex mixing followed by 10 min sonication in an ultrasonic bath. Mixtures were rotary evaporated to dryness and resuspended in $1.5 \mathrm{ml}$ sterile PBS (prepared using pyrogen-free water) and centrifuged at $13000 \mathrm{~g}$ for $10 \mathrm{~min}$ at $4{ }^{\circ} \mathrm{C}$. The supernatant was removed and the pelleted multilamellar vesicles were resuspended in $1.5 \mathrm{ml}$ sterile PBS and stored at $4{ }^{\circ} \mathrm{C}$.

Endotoxic activity of free LPS and liposome-encapsulated LPS was measured by the Limulus Amoebocyte Lysate (LAL) Endosafe KTA (Charles River) kit. Before performing the test, mixtures of free LPS (R1, R2, R3 and R4 core types) and liposome-incorporated LPS were diluted to obtain $0.4 \mathrm{ng}$ LPS $\mathrm{ml}^{-1}$. The amount of LPS incorporated into liposomes was measured by determining the endotoxic activity of the supernatant.

Chicken macrophage (HD11) cell culture. The HD11 cell culture, kindly given by Professor Constanze Bonifer from the University of Leeds, UK, was cultured in Dulbecco's modified Eagle's medium
(DMEM; Sigma) supplemented with $2 \%$ chicken serum (Sigma), $8 \%$ fetal calf serum (Sigma), $75 \mu \mathrm{g}$ chicken albumin $\mathrm{ml}^{-1}$ (Sigma), $2 \mathrm{mM}$ L-glutamine (Sigma), $100 \mathrm{IU}$ penicillin $\mathrm{ml}^{-1}$ and $100 \mathrm{mg}$ streptomycin $\mathrm{ml}^{-1}$ at $37{ }^{\circ} \mathrm{C}$ with $5 \% \mathrm{CO}_{2}$.

Comparison of NO production of macrophages treated with free LPS and liposome-encapsulated LPS. After incubation for $48 \mathrm{~h}$, the cells were harvested, counted and diluted in complete DMEM to obtain $5 \times 10^{6}$ cells $\mathrm{ml}^{-1}$. Cell suspension $(1 \mathrm{ml})$ was transferred to each well of three 24-well culture plates. Plates were incubated for $3 \mathrm{~h}$ at $37{ }^{\circ} \mathrm{C}$ in $5 \% \mathrm{CO}_{2}$. After incubation, supernatants were removed with non-adherent cells. Complete DMEM containing $1 \mu \mathrm{g}$ free LPS $\mathrm{ml}^{-1}$ was added to the wells of one plate, $1 \mu \mathrm{g}$ liposome-incorporated LPS $\mathrm{ml}^{-1}$ was added to the wells of the second plate and complete DMEM was added to the wells of the third plate. Supernatants of three wells in each plate were removed at $3 \mathrm{~h}$ intervals and centrifuged at $1500 \mathrm{~g}$ for $1 \mathrm{~min}$. The NO production was measured indirectly by determining the levels of nitrite $\left(\mathrm{NO}_{2}\right)$ accumulation in the supernatant using the Griess assay (Green et al., 1982).

Briefly, $100 \mu \mathrm{l}$ supernatant was added to a flat-bottomed microtitre plate and mixed with an equal volume of Griess reagent, which contains $1 \%$ sulphanilamide and $0.1 \%$ of naphthylethylenediamine dihydrochloride. Plates were read in an ELISA plate reader at $540 \mathrm{~nm}$ after $10 \mathrm{~min}$ incubation at room temperature.

Further, different concentrations ( $4 \mathrm{ng}, 40 \mathrm{ng}, 400 \mathrm{ng}, 2 \mu \mathrm{g}, 4 \mu \mathrm{g}$, $6 \mu \mathrm{g}, 8 \mu \mathrm{g}$ and $10 \mu \mathrm{g}$ ) of free and liposome-incorporated LPS were used to stimulate chicken macrophage cells $\left(5 \times 10^{6}\right)$. Cells were incubated at $37{ }^{\circ} \mathrm{C}$ in a $5 \% \mathrm{CO}_{2}$ incubator. Supernatants were collected after $18 \mathrm{~h}$ of incubation and tested as above.

Determination of expression of the inducible nitric oxide synthase (iNOS) gene of HD11 cells stimulated with free LPS and liposome-encapsulated LPS. An equal number of HD11 cells $\left(5 \times 10^{6}\right)$ were transferred to nine cell culture flasks $(25 \mathrm{ml})$ and incubated for $2 \mathrm{~h}$ at $37{ }^{\circ} \mathrm{C}$ in $5 \% \mathrm{CO}_{2}$. The supernatant was then removed and replaced in the first set of three flasks with $10 \mathrm{ml}$ complete DMEM with free LPS at $1 \mu \mathrm{g} \mathrm{ml}^{-1}$, in the second set (three flasks) with liposome-incorporated LPS at $1 \mu \mathrm{g} \mathrm{ml}^{-1}$ and in the third set of flasks with complete DMEM. The flasks were incubated at $37{ }^{\circ} \mathrm{C}$ in $5 \% \mathrm{CO}_{2}$ for $18 \mathrm{~h}$. Cells in all three sets of flasks were collected after $18 \mathrm{~h}$ using a sterile cell scraper and centrifuged at $4000 \mathrm{~g}$ for $5 \mathrm{~min}$. They were then counted and appropriately diluted to obtain $5 \times 10^{6}$ cells $\mathrm{ml}^{-1}$. Volumes $(1 \mathrm{ml})$ of each sample were transferred to microcentrifuge tubes and centrifuged at $4000 \mathrm{~g}$ for $5 \mathrm{~min}$. The supernatants were discarded and the mRNA was extracted from the cells using TRI Reagent (Sigma). DNA contamination in the samples was removed using the TURBO DNA-free kit (Ambion) following the manufacturer's instructions. The RNA samples were reverse-transcribed using the two-step protocol of the RETROscript RT-PCR kit (Ambion).

Semiquantitative RT-PCR to determine the expression of the iNOS gene. The purity of RNA samples was measured by both spectrophotometry and gel electrophoresis. The $A_{260} / A_{280}$ ratio was always higher than 1.94 .

The iNOS gene (F 5'-AATGCTGTGCCCATGGCAGTTTGCA-3', R $5^{\prime}$-TGTCGATGTCCCGCATGA-3') and the housekeeping gene encoding $\beta$-actin (F $5^{\prime}$-CCCCCGTGCTGTGTTCCCATCTATCG-3', R 5'-GGGTGCTCCTCAGGGGCTACTCTCAG-3') were amplified separately as described by Xing \& Schat (2000) in $25 \mu$ PCR mixture containing $2.5 \mu \mathrm{l} 5 \times$ PCR buffer, $4 \mathrm{mM} \mathrm{MgCl}_{2}, 30 \mathrm{pM}$ each forward and reverse primer (VH Bio), $1 \mu \mathrm{l}$ dNTP, 1 U Taq DNA polymerase (Promega) and $3 \mu \mathrm{l}$ cDNA. Conditions used for amplifications were: initial denaturation at $94{ }^{\circ} \mathrm{C}$ for 2 min followed by 35 cycles of $94{ }^{\circ} \mathrm{C}$ 
for $30 \mathrm{~s}, 65{ }^{\circ} \mathrm{C}$ for $30 \mathrm{~s}$ and $68{ }^{\circ} \mathrm{C}$ for $1 \mathrm{~min}$ with the addition of $5 \mathrm{~s}$ to each cycle from cycle 11 to 35 . Samples were electrophoresed on $1.5 \%$ agarose gels containing ethidium bromide at $100 \mathrm{~V}$ for $1 \mathrm{~h}$. Bands were visualized and densitometric analyses were carried out using the ChemImage analysis system (Alpha Innotech).

\begin{abstract}
Quantitative real-time PCR to determine the expression of interleukin-1 $\beta$ (IL-1/) and gamma-interferon (IFN- $\gamma$ ). The reverse-transcribed RNA samples described earlier were used for quantitative real-time PCR to determine the expression of IFN- $\gamma$ and IL- $1 \beta$. The published sequences (chicken IL-1 $\beta$ : F $5^{\prime}$-GCTCTACATGTCGTGTGTGATGAG-3'，R 5'-TGTCGATGTCCCGCATGA$3^{\prime}$; and chicken IFN- $\gamma$ : F 5'-GTGAAGAAGGTGAAAGATATCATGGA-3', R 5'-GCTTTGCGCTGGATTCTCA-3') were used to obtain primers (Moody et al., 2000). Quantitative real-time PCR was performed using SYBR Green JumpStart Taq ReadyMix PCR

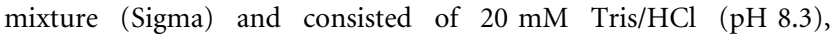
$100 \mathrm{mM} \mathrm{KCl}, 7 \mathrm{mM} \mathrm{MgCl}, 0.4 \mathrm{mM}$ each dNTP, stabilizers, $0.05 \mathrm{U}$ Taq DNA polymerase $\mu \mathrm{l}^{-1}$, JumpStart Taq Antibody and SYBR Green 1. Amplification and detection of products was performed using the Stratagene detection system with the following cycle conditions: one cycle of $50{ }^{\circ} \mathrm{C}$ for $2 \mathrm{~min}, 60{ }^{\circ} \mathrm{C}$ for $30 \mathrm{~min}$ and $95{ }^{\circ} \mathrm{C}$ for $5 \mathrm{~min}$ followed by 40 cycles of $94{ }^{\circ} \mathrm{C}$ for $20 \mathrm{~s}$ and $59{ }^{\circ} \mathrm{C}$ for $1 \mathrm{~min}$. The cDNA obtained from the macrophages stimulated with LPS was used as the standard sample.
\end{abstract}

Immunization of chickens. Day-old male chickens of the Lohmann Indian River broiler breed were obtained from a commercial hatchery and raised in a poultry house at the Veterinary Research Institute, Gannoruwa. Animal experiments were carried out according to the institutional guidelines.

Chickens were randomly assigned to four groups (12 birds in each group), wing banded and housed in separate rooms. All chickens were fed with commercial rations according to a standard schedule and water was made available ad libitum. A liposome-encapsulated mixture of complete LPS core types was diluted in sterile PBS to obtain LPS at $0.4,2$ and $10 \mu \mathrm{g} \mathrm{ml}^{-1}$ and $0.5 \mathrm{ml}$ was injected intramuscularly into birds in groups 1, 2 and 3, respectively, at 7 and 21 days of age. The birds in group 4, which served as the control, were injected intramuscularly with $0.5 \mathrm{ml}$ PBS.

Challenge. Strain E. coli O78 with R1 LPS core type was used to challenge birds as it has been identified as the most prevalent LPS core type among avian E. coli (Dissanayake et al., 2008). Bacteria were grown for $12 \mathrm{~h}$ at $37{ }^{\circ} \mathrm{C}$ in Brain Heart Infusion broth, washed in sterile PBS and diluted with PBS to a concentration of $1 \times 10^{6}$ c.f.u. $\mathrm{ml}^{-1}$. All chickens in groups $1,2,3$ and 4 were injected subcutaneously with $1 \mathrm{ml}$ E. coli O78 suspension at 28 days of age.

Carcasses of dead chickens were subjected to post-mortem examinations and pathological findings were recorded. Heart blood, liver and spleen of dead chickens were examined microbiologically following standard procedures. On day 38, all surviving birds were weighed, euthanized and necropsied and pathological findings were recorded.

Blood sampling and serum preparation. Blood samples were collected from the brachial vein of each bird on days 7, 21, 28 and 38 and allowed to clot at room temperature for $30 \mathrm{~min}$ before centrifuging at $4000 \mathrm{~g}$ for $10 \mathrm{~min}$ at $4{ }^{\circ} \mathrm{C}$. The serum was separated and stored at $-20{ }^{\circ} \mathrm{C}$ until analysed.

Determination of serum anti-LPS core antibody titres by ELISA. LPS core-polymyxin B sulphate complexes were prepared by a method modified from that of Scott \& Barclay (1987). Aqueous phenol-extracted LPSs of core types R1, R2, R3 and R4 were prepared at $1 \mathrm{mg} \mathrm{ml}^{-1}$ in pyrogen-free water and sonicated at $5 \mu \mathrm{m}$ for $30 \mathrm{~s}$ (MSE Soniprep sonicator). Equal volumes of the LPS solution and
$1 \mathrm{mg}$ polymyxin B sulphate $\mathrm{ml}^{-1}$ (Sigma) were mixed and sonicated as above. Polymyxin B sulphate-LPS core suspensions were transferred to MWCO 2000 dialysis tubing (Spectrapore) and dialysed overnight against 21 pyrogen-free water. The dialysed mixtures were transferred to glass bijou bottles and sonicated again under the same conditions to dissolve floccular masses. Mixtures were diluted in coating buffer (0.05 M sodium carbonate buffer, $\mathrm{pH} 9.6)$ at $1: 50$ and mixed thoroughly by vortex. Plates were coated by adding $100 \mu \mathrm{LPS}$ core-polymyxin B complex to each well (Costar Corning; high binding microtitre plate). To avoid coating large complexes, the suspensions were mixed intermittently. Plates were kept at $4{ }^{\circ} \mathrm{C}$ overnight, washed four times with PBS-Tween 20 (0.05\% Tween 20 in PBS, pH 7.4), blocked with $3 \%$ fish gelatin overnight at $4{ }^{\circ} \mathrm{C}$, washed again, dried and stored at $-20{ }^{\circ} \mathrm{C}$ until used. Serum samples were diluted $1: 200$ in PBS dilution buffer $(4 \%$, w/v, polyethylene glycol 8000 and $0.05 \%, \mathrm{v} / \mathrm{v}$, Tween $20, \mathrm{pH} 7.4$ ) and $100 \mu \mathrm{l}$ of each serum sample was added in duplicate to four microtitre plates each coated with a different core type. Only the dilution buffer was added to the wells of negative controls. A serum sample which gave the colour near to the mean in a preliminary titration was used as the standard and was included in each plate. Plates were incubated for $90 \mathrm{~min}$ at $37^{\circ} \mathrm{C}$, washed four times with PBS-Tween 20 and incubated with horseradish peroxidase-conjugated goat anti-chicken antibodies (Particell) diluted 1:10000 for $90 \mathrm{~min}$ at $37^{\circ} \mathrm{C}$.

One tablet of tetramethylbenzidine dihydrochloride (Sigma) and $2 \mu \mathrm{l}$ hydrogen peroxide $(30 \%, \mathrm{w} / \mathrm{v})$ were added per $10 \mathrm{ml} 0.05 \mathrm{M}$ phosphate citrate buffer ( $\mathrm{pH} 5.0$ ) and $100 \mu \mathrm{l}$ was added to each well. Plates were incubated at room temperature until the colour of the standard serum was close to that of the mean. The reaction was stopped by adding $50 \mu \mathrm{l} 2 \mathrm{M}$ sulphuric acid and plates were read at $450 \mathrm{~nm}$. Results were normalized to the standard before analysing.

Mortality and gross lesions. Chickens were observed daily for 6 days for signs of illness such as depression, ruffled feathers, anorexia, dyspnoea and mortality. On day 38, surviving chickens were killed, and gross lesions in the air sacs, liver and pericardial sac were scored on a scale of $0-3$ as described by Peighambari et al. (2002): $0=$ no lesions; $1=$ cloudy air sacs or mild pericarditis or hepatitis; $2=$ moderate airsacculitis, pericarditis or hepatitis; $3=$ severe airsacculitis, pericarditis or hepatitis. The air sacs, livers, pericardial sacs and heart blood were cultured for E. coli, which was identified by following standard bacteriological procedures, and a score of 1 was assigned for reisolation of the E. coli from each sample. A score of 10 was assigned for the birds which died after challenge.

Statistical analysis. Lesion scores were analysed using the KruskalWallis test and means were compared using the Mann-Whitney test (Minitab analytical software, version 14). Significance in differences of antibody titres for LPS core types between vaccinated and control groups was determined by two-way ANOVA and by Tukey Honest Significant Differences with 'R-work' software version 2.5.1 (http:// www.r-project.org/index.html). Differences were considered statistically significant if $P \leqslant 0.05$.

\section{RESULTS AND DISCUSSION}

\section{Potency of inducing LAL coagulation}

To ensure that the LPSs were properly incorporated, supernatants were tested by LAL assay. Apart from the supernatant with a 1:1 phospholipids:LPS ratio, which had an endotoxin concentration of $64 \mathrm{EU} \mathrm{ml}^{-1}$, all other supernatants contained comparatively low concentrations $\left(<8 \mathrm{EU} \mathrm{ml}^{-1}\right)$. Of the various concentrations tested $(1: 1$, 
$1: 10,1: 100$ and $1: 1000)$, the $10: 1$ concentration incorporated the maximum amount of LPS and was selected for further studies.

\section{Responses of macrophages to free and liposome- encapsulated LPS}

The activity of LPS on cells is usually determined by the capacity to induce various cytokines as it plays a key role in both inflammation and immune responses. Unlike in mammals, the role of cytokines and related proteins is less well described in avian species (Wigley \& Kaiser, 2003). Assessment of the levels of human and murine cytokines is comparatively easy as a number of commercial kits are available. In chickens, there are no reliable bioassays to measure most of these cytokines. Hence the potency of stimulating macrophages was assessed in the present study by the level of NO production and gene expression specific for IL- $1 \beta$, IFN $-\gamma$ and iNOS.

\section{NO production and iNOS gene expression}

Variations of NO production by HD11 cells stimulated over $24 \mathrm{~h}$ with free and liposome-encapsulated LPS are shown in Fig. 1. The cells treated with free LPS showed significantly higher levels of NO when compared to the cells treated with liposome-encapsulated LPS. Further, NO production by macrophages activated by free LPS $(1 \mu \mathrm{g}$ $\mathrm{ml}^{-1}$ ) increased with the time of treatment, and the cells incubated for $21 \mathrm{~h}$ showed the highest NO production. Macrophages treated with liposome-encapsulated LPS produced less than $5 \mu \mathrm{M}$ nitrite and this did not increase remarkably over the period of time observed.

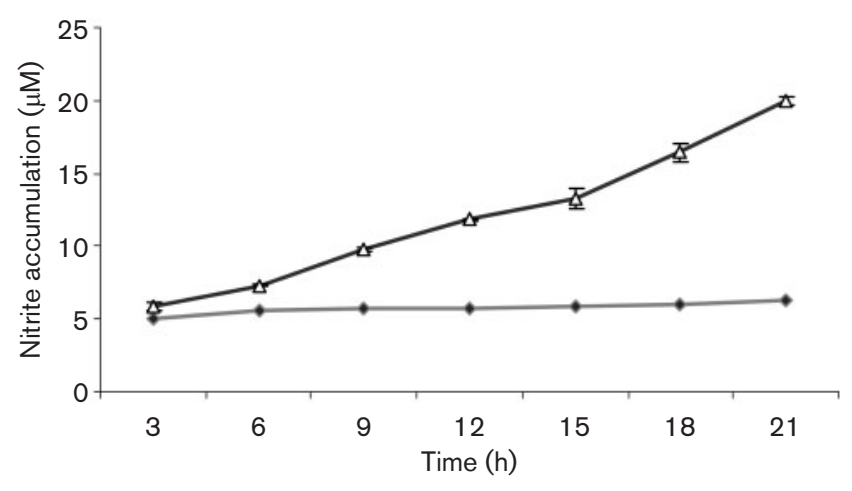

Fig. 1. Nitrite accumulation in chicken macrophage cells (HD11) exposed to a $1 \mu \mathrm{g} \mathrm{ml}^{-1}$ mixture of free LPS core types $(\triangle)$ and $1 \mu \mathrm{g} \mathrm{ml}^{-1}$ of liposome-incorporated LPS core types $(\lambda)$ for $21 \mathrm{~h}$ as detected by the Griess assay. Samples were collected at $3 \mathrm{~h}$ intervals and three replicate samples were obtained at each time point. Each data point represents the mean nitrite levels $(\mu \mathrm{M})$. At each time point, nitrite accumulation in free LPS-treated cells was significantly higher than that in liposome-encapsulated LPStreated cells $(P<0.05)$. Background nitrite levels in resting cells were less than $5.4 \mu \mathrm{M}$ at each time point.
Fig. 2 shows NO production by macrophages treated with different concentrations of free LPS and the liposomeencapsulated LPS. Nitrite production by macrophages treated with free LPS was remarkably enhanced with increasing dose while the cells treated with liposomeencapsulated LPS elicited little increase in NO production with increasing dose.

No detectable iNOS-specific mRNA expression was observed in untreated cells (Fig. 3). Intensities of the bands specific for iNOS and $\beta$-actin were measured in each sample and the iNOS/ $\beta$-actin ratios were calculated and are shown in Table 1. The cells treated with free LPS showed significantly higher $(P<0.05)$ iNOS-specific mRNA expression than the cells treated with liposome-encapsulated LPS. It is important to note that the cells treated with liposome-encapsulated LPS showed little NO production and the mRNA expression specific for iNOS was comparatively lower than that of cells treated with free LPS.

\section{Quantification of IL-1 $\beta$ and IFN- $\gamma$ expression by quantitative RT-PCR}

Cells treated with liposome-encapsulated LPS and free LPS showed 1.22-fold and 1.58-fold mRNA expression for IL$1 \beta$ and 1.299-fold and 1.61-fold mRNA expression for IFN$\gamma$. Even though the cells exposed to free LPS showed higher mRNA expression for IL- $1 \beta$ and IFN- $\gamma$ than the cells exposed to liposome-encapsulated LPS, the differences were not statistically significant. In chickens, NO production is also considered as an assay to measure IFN- $\gamma$-like activity (Kaiser et al., 2000) and is generally referred to as macrophage activating factor assay. The real-time quantitative RT-PCR results did not indicate a remarkable difference in the expression of IFN- $\gamma$-specific mRNA between cells treated with free LPS and those treated with liposome-encapsulated LPS. However, the NO production bioassay for IFN- $\gamma$ indicated significantly higher levels of IFN- $\gamma$-like activity of cells treated with free LPS than for the cells treated with liposome-encapsulated LPS. It may be important to note that the mRNA levels do not necessarily reflect release of biologically active protein (Wigley \& Kaiser, 2003).

Ideally, it would have been better if primary peritoneal macrophage cells had been used to determine nitrite accumulation and gene expression specific for iNOS, IL-1 $\beta$ and IFN- $\gamma$ rather than the chicken macrophage cell line (HD11), as the primary cells are likely to have slower kinetics than cell lines.

\section{Immunization study}

Serum antibodies reactive with LPS core types R1, R2, R3 and R4 were detected in all chickens prior to immunization but with a wide range of variation between individuals. At this stage, the lowest mean antibody titre was against the R2 LPS core type and highest mean antibody titres were against the R3 or R4 LPS core types. 


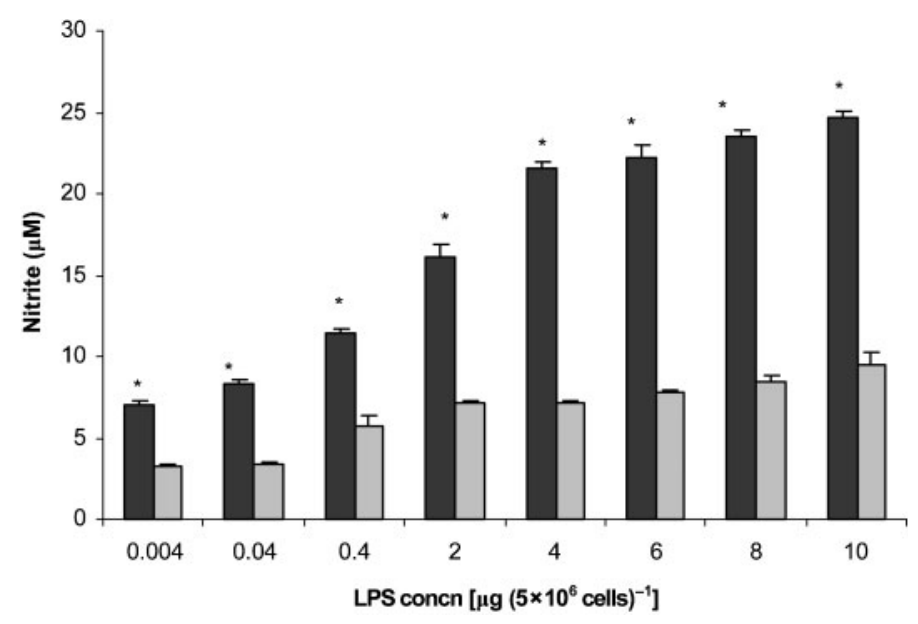

Fig. 2. Nitrite accumulation in macrophages exposed to different concentrations of free (black bars) and liposome-encapsulated (grey bars) LPS core types for $18 \mathrm{~h}$. Nitrite accumulation was measured in the culture supernatant using the Griess assay. Each bar represents the mean nitrite levels in culture supernatant of three replicate wells and error bars represent the standard deviation. Background nitrite levels in resting cells were less than $5 \mu \mathrm{M}$ at each time point. ${ }^{*} P<0.01$ compared with liposome-encapsulated LPStreated cells.

On day 21 (14 days after the first immunization), a significant rise $(P<0.001)$ in anti-LPS core specific IgG responses was observed in all chickens including those in the unimmunized group. It is apparent that the anti-LPS core antibody titres increase with age, and this is no doubt due to environmental exposure.

The R1, R2, R3 and R4 LPS core specific IgG responses of chickens immunized with different doses of liposomeencapsulated LPS and those of non-immunized chickens as detected by ELISA $\left(A_{450}\right)$ are shown in Fig. 4 . The group of chickens (group 3 ) that received $5 \mu \mathrm{g}$ liposome-encapsulated LPS showed significantly high $(P<0.001)$ mean LPS core specific IgG responses to types $\mathrm{R} 2$ and $\mathrm{R} 3$. The same group of chickens also showed the highest mean IgG response specific for the R4 LPS core type. However, that difference was not statistically significant. The mean antibody titres specific for R1 and R4 core types in the group of chickens immunized with the lowest dose of vaccine $(0.2 \mu \mathrm{g})$ were lower than those of the unimmunized group. When compared with the chickens in groups 2 and 3, LPS core-specific antibody responses of the chickens immunized with the lowest dose and of the non-immunized chickens showed high individual variations even though they develop high mean antibody titres, particularly for the R1 LPS core type.

Table 2 shows the results of the challenge study. The group that received the lowest dose of vaccine $(0.2 \mu \mathrm{g}$; group 1$)$ had three deaths and those birds died 3 consecutive days after challenging with the E. coli O78 strain. No mortalities were observed in groups that received $1 \mu \mathrm{g}$ (group 2) and $5 \mu \mathrm{g}$ (group 3) liposome-encapsulated LPS. One bird from the control group died within $24 \mathrm{~h}$ of challenge. Although the mortality rate was higher in group 1 , the number of clinical infections was higher in the control group. Five of the 12 birds from the control group showed clinical signs of colibacillosis within $24 \mathrm{~h}$ of challenge. Two birds from group 2 and two birds from group 3 also showed clinical signs within 2 days of challenge. All these affected birds survived until they were euthanized ( 7 days after challenge) but showed decreased weight gain, difficulties in walking and respiratory rales, and post-mortem examinations revealed mild to severe pericarditis, perihepatitis and airsacculitis. When the samples with those lesions were cultured on blood and MacConkey agar, E. coli was isolated from all samples. All birds showed a yellow circumscribed lesion at the site of subcutaneous challenge. No lesions were observed at the site of vaccination.

Groups vaccinated with $1 \mu \mathrm{g}$ and $5 \mu \mathrm{g}$ liposome-encapsulated LPS exhibited a significantly lower $(P<0.05)$ total lesions score when challenged. In contrast, the vaccine containing $0.2 \mu \mathrm{g}$ LPS provided little protection and the lesions score results were very similar to those of the nonimmunized group. The weight gain of the three

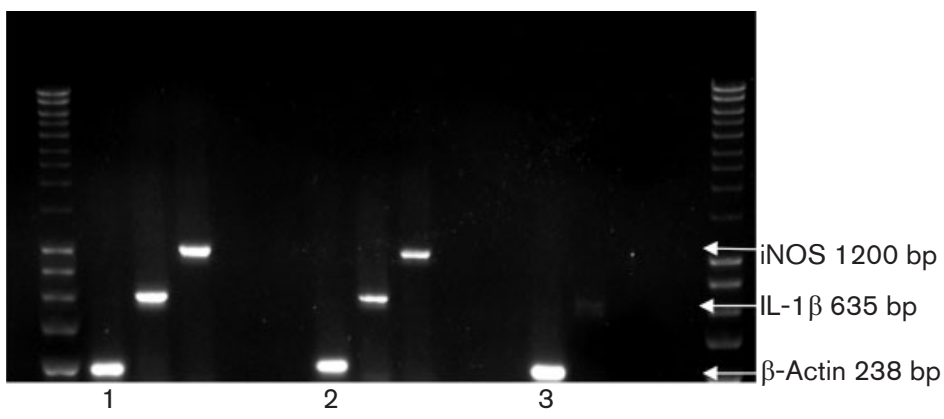

Fig. 3. Expression of mRNA specific for iNOS and IL-1 $\beta$ in chicken macrophage cells (HD11) when exposed to free or liposome-encapsulated LPS $\left(1 \mu \mathrm{g} \mathrm{ml}^{-1}\right)$ by semiquantitative RTPCR. (1) Cells treated with free LPS; (2) cells treated with liposome-incorporated LPS; (3) untreated cells. The gene encoding $\beta$-actin was used as the housekeeping gene. HyperLadder (Bioline) was used for DNA quantification. 
Table 1. Expression of mRNA specific for iNOS, IL-1 $\beta$ and IFN- $\gamma$ in avian macrophages (HD11) treated with free and liposome-encapsulated LPS as detected by semiquantitative RT-PCR (iNOS gene) or by quantitative real-time PCR (IL-1 $\beta$ and IFN- $\gamma$ )

The housekeeping gene encoding $\beta$-actin was used to account for the variations in the amount of RNA used for each reaction. Mean values of triplicate samples were used for calculations. mRNA values were corrected for the variations in input RNA and the corrected data are shown as fold change when compared to the mRNA expression of untreated cells.

\begin{tabular}{|lccccc|}
\hline Treatment & $\begin{array}{c}\text { Semiquantitative } \\
\text { RT-PCR }\end{array}$ & & \multicolumn{2}{c|}{$\begin{array}{c}\text { Quantitative } \\
\text { RT-PCR }\end{array}$} \\
\cline { 2 - 2 } \cline { 5 - 6 } & iNOS & & IL-1 $\boldsymbol{\beta}$ & IFN- $\boldsymbol{y}$ \\
\hline Free LPS-treated cells & 4.98 & & 1.58 & 1.61 \\
Liposome-incorporated & 3.47 & & 1.22 & 1.29 \\
LPS-treated cells & & & & \\
\hline
\end{tabular}

vaccinated groups was higher than that of the control group.

The prophylactic vaccine developed by Bennett-Guerrero et al. (2000) by incorporating complete LPS cores of several species of Gram-negative bacteria into liposomes with the intention of using in at-risk surgical patients was reported to be broadly cross-reactive and cross-protective. Chhibber et al. (2004) also reported that liposome-encapsulated LPS of Klebsiella pneumoniae was non-pyrogenic, non-toxic and more effective in providing protection against lobar pneumonia in a mouse model. The results of our study indicated that the vaccination of chickens with appropriate doses of liposome-encapsulated complete LPS vaccine can induce protection against E. coli infection. The birds vaccinated with an appropriate dose of vaccine were less commonly affected than the non-immunized birds. However, it is important to note that the birds immunized with the lowest dose of vaccine were even more susceptible to colisepticaemia than the non-immunized group. Previous studies have demonstrated that the magnitude of the specific antibody response to some bacterial LPSs can be increased or decreased by prior exposure (priming) with a single injection of a subimmunogenic dose of LPS (Elkins et al., 1987). In an experiment carried out using mice that were low dose primed and then immunized with suboptimal, optimal or supra-optimal amounts of E. coli O55 and Serratia marcescens LPS, the magnitude of the specific plaque forming cell responses to all immunizing doses of homologous LPS was reduced by that low dose priming.

Even though the laboratory studies indicated that there was a protection against the experimental challenge, a field trial needs to be carried out because the chickens used in this experiment are less likely to encounter the stress factors experienced by chickens reared under field conditions. Also, the challenge in the natural environment may be quite different from the massive exposure that is used experimentally. The efficacy of a vaccine is usually determined by experimental infection and in such experiments it is important to mimic the natural conditions. In the present study, birds were challenged through the subcutaneous route, which is less relevant to their natural exposure. More often, E. coli enters chickens through the respiratory route and it would be more appropriate if the challenge study were done so as to facilitate the organisms entering the body through that route. As the broilers are at great risk of colibacillosis at 3-4 weeks of age, an attempt was made to challenge the birds at that stage.

Gibbs et al. (2004) tested human and cattle sera for the presence of antibodies reactive with each of the five LPS core types and reported that R4-specific anti-LPS core antibody titres were significantly high in both cases. Results of the present study revealed that the chickens also induced high R4 core-specific antibodies even though the values were not statistically significant. However, the results of

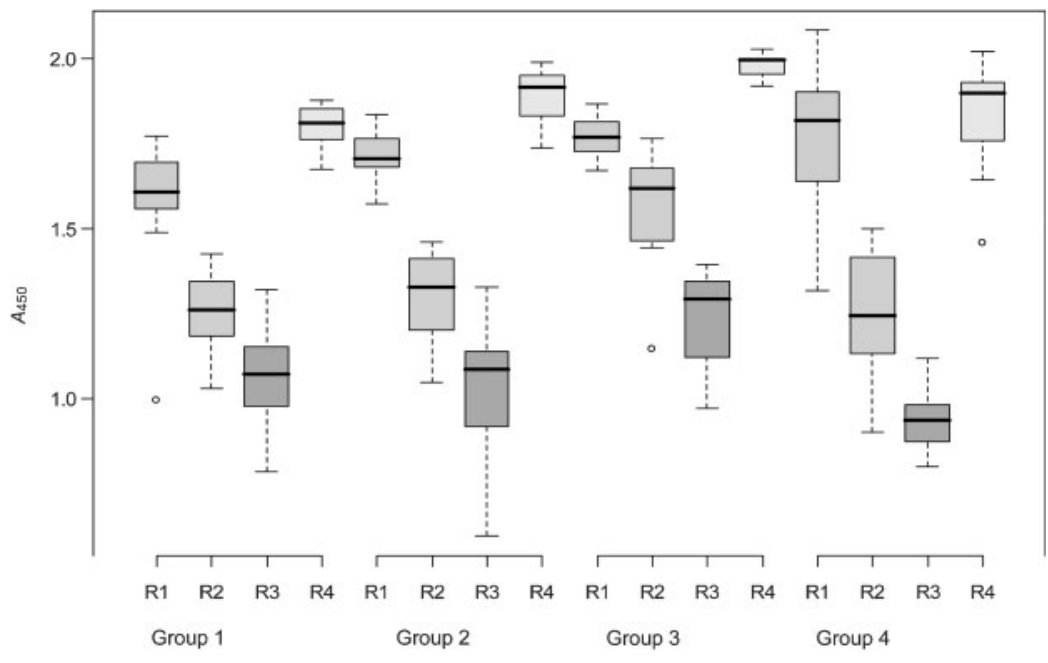

Fig. 4. Anti-LPS core antibody titres for broiler chickens vaccinated with different doses of the liposome-encapsulated mixture of LPS core types and the unvaccinated control group as detected on day 28 of age. Chickens were vaccinated intramuscularly with $0.2 \mu \mathrm{g}$ (group 1), $1 \mu \mathrm{g}$ (group 2) and $5 \mu \mathrm{g}$ (group 3) LPS on days 7 and 21 . Chickens in the unvaccinated control group (group 4) were given sterile PBS intramuscularly. R1, R2, R3 and R4 are the different LPS core types. In the box plot, the line in the box represents the median, the top and bottom lines of the box represent 75 and 25 percentiles, respectively, and the top and bottom whiskers represent the 90 and 10 percentiles, respectively. 
Table 2. Mortality, lesions score, E. coli reisolation and mean body weight of chickens immunized with two doses of liposomeencapsulated LPS and the unvaccinated control group after challenging with E. coli O78

Chickens in groups 1, 2 and 3 were given $0.2 \mu \mathrm{g}, 1 \mu \mathrm{g}$ and $5 \mu \mathrm{g}$ liposome-encapsulated LPS vaccine intramuscularly on days 7 and 21 of age and challenged with E. coli $\mathrm{O} 78$ on day 28 of age. The group 4 chickens were given sterile PBS intramuscularly. Birds surviving 10 days after challenge were euthanized and lesions scores were recorded. Gross lesions in the air sacs, liver and pericardial sacs were scored on a scale of 0-3: 0, no lesions; 1, cloudy air sacs or mild pericarditis or hepatitis; 2, moderate airsacculitis, pericarditis or hepatitis; 3 , severe airsacculitis, pericarditis or hepatitis.

\begin{tabular}{|c|c|c|c|c|c|c|c|c|}
\hline \multirow[t]{2}{*}{ Group } & \multirow[t]{2}{*}{ Dose } & \multirow[t]{2}{*}{ Mortality rate } & \multicolumn{3}{|c|}{ Mean lesions score of survivors } & \multirow{2}{*}{$\begin{array}{c}\text { Reisolation of } \\
\text { E. coli }\end{array}$} & \multirow{2}{*}{$\begin{array}{c}\text { Total lesions } \\
\text { score }\end{array}$} & \multirow{2}{*}{$\begin{array}{l}\text { Mean body } \\
\text { weight (g) }\end{array}$} \\
\hline & & & Air sacs & Liver & Heart & & & \\
\hline 2 & $1 \mu \mathrm{g}$ & 0 & $0.66 \dagger$ & 016 & $0.33 \dagger$ & $6 / 36(16 \%)$ & $1.2 \dagger$ & $2216 \pm 156$ \\
\hline 3 & $5 \mu \mathrm{g}$ & 0 & $0.66 \dagger$ & 0.33 & $0.33 \dagger$ & $8 / 36(22 \%)$ & $1.3 \dagger$ & $2188 \pm 160$ \\
\hline
\end{tabular}

${ }^{\star}, \dagger, \ddagger$ Differences in symbols indicate statistical significance $(P \leqslant 0.05)$.

previous studies (Gibb et al., 1992; Gibbs et al., 2004; Dissanayake et al., 2008) revealed that the R1 core type is the most common and the R4 LPS core type rarely occurred among commensal isolates. It is therefore unlikely that the chickens are exposed more frequently to the R4 core type.

In early studies, the liposome-encapsulated LPS vaccines were adjuvanted with aluminium hydroxide prior to administration (Bennett-Guerrero et al., 2000). Aluminium hydroxide has long been used as an adjuvant which can potentiate the IgG response of the antigen. In the present experiment, no adjuvant was used, as the aluminium adjuvant vaccines tend to become encapsulated by the granulomatous inflammatory response, which affects meat quality (Trampel \& Griffith, 1997).

As the core oligosaccharide of bacterial LPS is antigenically conserved across different serotypes, antibodies reactive with the LPS core will provide cross-serotype protection. Therefore, the liposome-encapsulated mixture of complete LPS vaccine might be able to protect chickens in the field against E. coli infection.

\section{ACKNOWLEDGEMENTS}

Partial financial support given by NSF (grant no. RG/2004/V/03) and Commonwealth split-site doctoral scholarship to D. R. A. D. is highly acknowledged. The authors would also like to thank $\operatorname{Dr} \mathrm{A}$. Arulkanthan for his help in statistical analysis.

\section{REFERENCES}

Arp, L. H. (1980). Consequences of active or passive immunization of turkeys against Escherichia coli O78. Avian Dis 24, 808-815.

Bennett-Guerrero, E., McIntosh, T. J., Barclay, G. R., Snyder, D. S., Gibbs, R. J., Mythen, M. G. \& Poxton, I. R. (2000). Preparation and preclinical evaluation of a novel liposomal complete-core lipopolysaccharides vaccine. Infect Immun 68, 6202-6208.
Chhibber, S., Wadhwa, S. \& Yadav, V. (2004). Protective role of liposome incorporated lipopolysaccharide antigen of Klebsiella pneumoniae in a rat model of lobar pneumonia. Jpn J Infect Dis 57, $150-155$.

Deb, J. R. \& Harry, E. G. (1976). Laboratory trials with inactivated vaccines against Escherichia coli 078: K80 infection in fowls. Res Vet Sci 20, 131-138.

Dijkstra, J., Mellors, J. W., Ryan, J. L. \& Szoka, F. C. (1987). Modulation of the biological activity of bacterial endotoxin by incorporation into liposomes. J Immun 138, 2663-2670.

Dijkstra, J., Larrick, J. W., Ryan, J. L. \& Szoka, F. C. (1988). Incorporation of LPS in liposomes diminishes its ability to induce tumoricidal activity and tumor necrosis factor secretion in murine macrophages. J Leukoc Biol 43, 436-444.

Dijkstra, J., Mellors, J. W. \& Ryan, J. L. (1989). Altered in vivo activity of liposome-incorporated lipopolysaccharide and lipid A. Infect Immun 57, 3357-3363.

Dissanayake, D. R. A., Wijewardana, T. G., Gunawardena, G. A. \& Poxton, I. R. (2008). Distribution of lipopolysaccharide core types among avian pathogenic Escherichia coli in relation to the major phylogenetic groups. Vet Microbiol 132, 355-363.

Elkins, K. L., Stashak, P. W. \& Baker, P. J. (1987). Mechanisms of specific immunological unresponsiveness to bacterial lipopolysaccharide. Infect Immun 55, 3093-3102.

Erridge, C., Stewart, J., Bennett-Guerrero, E., McIntosh, T. J. \& Poxton, I. R. (2002). The biological activity of a liposomal complete core lipopolysaccharide vaccine. J Endotoxin Res 8, 39-46.

Frommer, A., Freidlin, P. J., Bock, R. R., Leitner, G., Chaffer, M. \& Heller, E. D. (1994). Experimental vaccination of young chickens with a live, non-pathogenic strain of Escherichia coli. Avian Pathol 23, 425433.

Galanos, C. \& Lüderitz, O. (1984). Lipopolysaccharide: properties of an amphipathic molecule. In HandBook of Endotoxin. 1. Chemistry of Endotoxin, pp. 46-58. Edited by E. Th. Rietschel. Amsterdam: Elsevier.

Gibb, A. P., Barclay, G. R., Poxton, I. R. \& di Padova, F. (1992). Frequencies of lipopolysaccharide core types among clinical isolates of Escherichia coli defined with monoclonal antibodies. J Infect Dis 166, 1051-1057.

Gibbs, R. J., Stewart, J. \& Poxton, I. R. (2004). The distribution of, and antibody response to, the core lipopolysaccharide region of 
Escherichia coli isolated from the faeces of healthy humans and cattle. J Med Microbiol 53, 959-964.

Green, L. C., Wagner, D. A., Glogowski, J., Skipper, P. L., Wishnok, P. S. \& Tannenbaum, S. R. (1982). Analysis of nitrate, nitrite and [15N]nitrate in biological fluids. Anal Biochem 126, 131-138.

Gyimah, J. E. \& Panigrahy, B. (1985). Immunogenicity of an Escherichia coli (serotype O1) pili vaccine in chickens. Avian Dis 29, 1078-1083.

Hancock, I. C. \& Poxton, I. R. (1988). Bacterial Cell Surface Techniques, pp. 90-93. Chichester, UK: Wiley.

Kaiser, P., Rothwell, L., Galyov, E. E., Barrow, P. A., Burnside, J. \& Wigley, P. (2000). Differential cytokine expression in avian cells in response to invasion by Salmonella typhimurium, Salmonella enteritidis and Salmonella gallinarum. Microbiology 146, 32173226.

Kariyawasam, S., Wilkie, B. N., Hunter, D. B. \& Gyles, C. L. (2002). Systemic and mucosal antibody responses to selected cell surface antigens of avian pathogenic Escherichia coli in experimentally infected chickens. Avian Dis 46, 668-678.

Manthey, C. L. \& Vogel, S. N. (1994). Elimination of trace endotoxin protein from rough chemotype LPS. J Endotoxin Res 1, 84-92.

Moody, A., Sellers, S. \& Bumstead, N. (2000). Measuring infectious bursal disease virus RNA in blood by multiplex real-time quantitative RT-PCR. J Virol Methods 85, 55-64.

Morrison, D. C. \& Ryan, J. L. (1987). Endotoxins and disease mechanisms. Annu Rev Med 38, 417-432.

Müller-Loennies, S., Di Padova, F., Brade, L., Brade, H. \& Rietschel, E. Th. (2005). Anti-endotoxin antibodies - a cross-reactive and crossprotective monoclonal antibody against a conserved epitope of
Escherichia coli and Salmonella enterica. Intensivmed Notfallmed 42, 27-38.

Nagaraja, K. V., Emery, D. A., Jordan, K. A., Sivanandan, V., Newman, J. A. \& Pomery, B. S. (1984). Effect of ammonia on the quantitative clearance of Escherichia coli from lungs, air sacs and livers of turkeys aerosol vaccinated against Escherichia coli. Am J Vet Res 45, 392-395.

Parmentier, H. K., Klompen, A. L., De Vries Reilingh, G. \& Lammers, A. (2008). Effect of concurrent intratracheal lipopolysaccharide and human serum albumin challenge on primary and secondary antibody responses in poultry. Vaccine 26, 5510-5520.

Peighambari, S. M., Hunter, D. B., Schewen, P. E. \& Gyles, C. L. (2002). Safety, immunogenicity and efficacy of two Escherichia coli cya, crp mutants as vaccines for broilers. Avian Dis 46, 287-297.

Poxton, I. R. (1995). Antibodies to lipopolysaccharide. J Immunol Methods 186, 1-15.

Scott, B. B. \& Barclay, G. R. (1987). Endotoxin-polymyxin complexes in an improved enzyme-linked absorbent assay for IgG antibodies in blood donor sera to Gram-negative endotoxin core glycolipids. Vox Sang 52, 272-280.

Trampel, D. W. \& Griffith, R. W. (1997). Efficacy of aluminum hydroxide-adjuvanted Escherichia coli bacterin in turkey poults. Avian Dis 41, 263-268.

Westphal, O. (1975). Bacterial endotoxin. Int Arch Allergy Appl Immunol 49, 1-43.

Wigley, P. \& Kaiser, P. (2003). Avian cytokines in health and disease. Rev Bras Cienc Avic 5, 1-14.

Xing, Z. \& Schat, K. A. (2000). Expression of cytokine genes in Marek's disease virus infected chickens and chicken embryo fibroblasts cultures. Immunology 100, 70-71. 